\title{
Depressive Symptoms Life Satisfaction and Cognitive Health Status Among University Students in Nigeria by Gender and Ethnicity
}

\author{
Ezenna Michael Agwu ${ }^{1, *}$, Stephen Draper ${ }^{2}$, Mark De Ste Croix ${ }^{2}$ \\ ${ }^{1}$ Department of Public Health, Mother Teresa Public Health Research Institute, Aba, Nigeria \\ ${ }^{2}$ Department of Sports Physiology, Faculty of Applied Sciences, University of Gloucestershire, Gloucester, United Kingdom
}

Email address:

ezenna2015@yahoo.com (E. M. Agwu)

*Corresponding author

\section{To cite this article:}

Ezenna Michael Agwu, Stephen Draper, Mark De Ste Croix. Depressive Symptoms Life Satisfaction and Cognitive Health Status Among University Students in Nigeria by Gender and Ethnicity. American Journal of Health Research. Vol. 5, No. 2, 2017, pp. 25-37. doi: 10.11648/j.ajhr.20170502.12

Received: October 16, 2016; Accepted: January 19, 2017; Published: March 3, 2017

\begin{abstract}
Background: The health determinant model indicates that certain socio-cultural, socio-demographic, environmental, and lifestyle factors influence health status and wellbeing of any population group in any given nation Previous studies have suggested the need for regional and interregional comparison of health inequalities due to the interaction of these factors. Aims: This study investigated mental health indicators and cognitive health status by sex and ethnicity among university students in Nigeria. Method: The study was cross sectional. Full time university students were recruited from six universities within the major three ethnic groups in Nigeria. Data collection was with an anonymous questionnaire. One thousand five hundred and forty-nine responses were valid, while 563 responses were rejected for missing data especially sex and ethnicity. The variables examined were, psychosomatic health complaints and cognitive behaviours. Descriptive tests, chisquare tests and analysis of variance (ANOVA) tests were conducted. Results: With regard to mental health indicators, the results showed that while depression indicate significant differences by gender and ethnicity, life satisfaction showed significant differences by ethnicity alone. Cognitive health status showed sex*ethnicity interaction effect for self-efficacy, sense of coherence and powerful others locus of control. Conclusion: The findings indicated that the mental health of female students in the sample was poorer than those of male students; with female students from the Hausa ethnic group, demonstrating the worst possible health outcome.
\end{abstract}

Keywords: Mental Health, Cognitive Health, Health Status, Gender Health Inequality, Ethnic Health Inequality, Health Evaluation, Health Evidence

\section{Introduction}

Despite evidence of poor health and prevalence of risky health behaviours, literature indicates that university students are the most under-researched group, with regard to their health and lifestyle patterns (Van Rensenburg \& Surujlal, 2013). Moreover, university students represent a major segment of the young adult population (Wang et al., 2013). They typically enter a dynamic transitional period of new independence from their parents that is characterised by rapid, interrelated changes in body, mind and social relationships (Mikolajczyk et al., 2008; Pullman et al., 2009).
In addition, they experience a new environment that generally involves increased workload and stress, and altered patterns of life, which are significant contributors of unhealthy lifestyles (Ulla-Diaz \& Perez Fortis, 2010).

There is evidence that majority of university students are minimally engaged in health promoting behaviours and exhibit behavioural health risk, such as tobacco use, alcohol and drug abuse, unhealthy diet and sedentary habits (Hasihasanoglu et al., 2011; Aldeen \& Ibrahim, 2014). More so, health risk associated diseases such as depression, psychosomatic complaints are also common among university students (Adewuya, et al., 2006). 
The theoretical framework for the current study was formulated primarily within the context of the social determinants of health. The WHO (2013) defined the social determinants of health as "the circumstances in which people are born grow up, live, work and age, and the systems put in place to deal with illness. The health and well-being of individuals and populations across all age groups is influenced by a range of factors both within and outside the individual's control (Azevedo et al., 2007; Dugdill et al., 2009; Murphy et al., 2009). These multiple factors include demographic, biological, emotional, cultural variables, social attributes and environmental factors (Trust et al., 2002; Cavill et al., 2006). One model, which captures the interrelationships between health determinant factors, is the Dahlgren and whitehead (1991) 'Rainbow Model', which describes the layers of influence on an individual's potential for health. These factors are classified into two: those that are fixed (core non - modifiable factors), such as age, sex, ethnicity and genetic factors on one hand and on the other hand is a of potentially, modifiable factors expressed as a series of layers of influence including, personal lifestyle, the physical and social environment and wider socio - economic, cultural, and environmental conditions. Dahlgren and Whitehead's (1991) model explained how a range of different factors can influence personal and community health.

To better understand socioeconomic status, social support, body image perception and depression among university students in Nigeria, a cross sectional survey was undertaken, which to our knowledge is the first of its kind in Nigeria. Inter-cultural comparative studies on student's lifestyle and health status will contribute to the improvement of health of university student's, especially in developing countries where there is paucity of research, among the students population.

Depression

According to the World Federation for Mental Health, "depression is a common mental disorder, characterized by sadness, loss of interest or pleasure, feelings of guilt or low self-worth, disturbed sleep or appetite, feelings of tiredness and poor concentration" (2009 p. 3). Consequently, an individual who has good mental health will be able to realize his or her own abilities, can cope with the stress of everyday life, be able to work productively and contribute to his or her community (WHO, 2005). Students commonest challenge to depression is stress (Seyedfatemi et al., 2007; El Gilany et al., 2009) and several factors have been reported to increase stress among university students such as academic workload, chronic illness, and financial problems (DeRoma et al., 2009; Lindsey et al., 2009).

Adewuya et al. (2006), in a cross sectional study, examined the socio-demographic correlates of depressive disorder among students in a university in western Nigeria. Student's depressive disorder was identified using the Mini International Neuro-psychiatric Interview (MINI). The result showed that overall $18 \%$ of students met the criteria for depressive disorders, with $3 \%$ having major depressive disorders and $6 \%$ having minor depressive disorders. The study also reported that students lifestyles especially alcohol and smoking were significantly associated with students reported depression.

While some studies found that female students reported depression more than male students (e.g. Dahlin et al., 2005; Mikolajcyzk et al., 2008), others found no significant differences between male and female students (e.g. Aniebue and Onyems, 2008; Bayran and Bilgel, 2008). However, Zawawi and Hamaideh (2009) suggested that the higher ratio of female students in sample size to male students in most studies might help to explain the observed higher frequency of female students reporting depression than male students. On the other hand, Dusselier et al. (2005) postulated that gender differences in stress and depression among university students might be due to women's stronger determination to succeed academically, which might give rise to a greater level of stress.

Life satisfaction

Life satisfaction was postulated as a subjective evaluation of the overall quality of life (Diener et al., 2005). On the other hand, it is a general indication of how a person perceives his or her life has been and how he or she may feel about how it is going in the future. There is evidence that low life satisfaction and poor quality of life can predict the onset of depression, and psychological disorder up to two years prior to diagnosis (Huebner, 2004). On the other hand, there is evidence that good mental health correlates positively with high scores in student's life satisfaction and quality of life (Viren et al., 2007).

Few studies that examined life satisfaction among university students showed that ethnicity, gender and sociodemographic factors (e.g. financial worries, concerns for future careers and personal illness), are among the factors that more commonly affect student's rating of their life satisfaction (e.g. Stock et al., 2007; Sabbaah et al., 2013). An earlier study by David (2001) provided evidence of cultural differences in student's satisfaction with life, with students from America and North America being more satisfied than students from Asia and Africa. The study argued that the socio-economic status of a nation may be a factor in people's rating of their life satisfaction. On the contrary, Mathney et al. (2004) found among university students in Turkey, that life satisfaction, showed no differences with ethnicity and culture. However, the study found a significant gender difference among the students, with male students scoring higher than female students did.

\section{Locus of control}

Locus of control refers to beliefs about responsibility for outcomes, it indicates both process of attainment and of a desired outcome (Michinove, 2005). The concept comprises of three different forms of control, including self, chance and others. There is evidence that locus of control is an attribute which is necessary for behavioural change and consequently contributes to good health. People who possess internal locus of control usually feel that they have control over situations around them, can influence events and perceive themselves as competent to predict what happens to them (Zawawi et al., 2009). In contrast, people characterized by external locus of 
control usually attribute events around them to forces beyond their control and such forces are said to be externally located (Zawawi et al., 2009). The ability of an individual to effect a positive health change and self-improvement in the times of challenges and difficulties is the exact summation of his or her locus of control. (Michinov, 2005). In contrast, students with external locus reported higher frequency of failure, illness and withdrawal from college (Pugliese, 1994).

Self-efficacy According to Bandura (1997) "self-efficacy is the beliefs in one's own capacity to organize and execute the courses of action required to manage prospective situations."

Cognitive factors have a significant effect on health status and lifestyle behaviours (Wardle et al., 2004; Akinsola, 2009). Research studies indicate that cognitive factors exert their effect by promoting individual's health behaviour change, which in turn promotes health status (Ying et al., 2007; Zawawi \& Hamaideh, 2009). Empirical evidence from students based studies showed that high scores in selfefficacy, leads to more adaptive coping, more effort in the goal-striving process, higher engagement in important goals, behaviours change and good health (Mikolajczyk et al., 2008; Jegede, 2009; Onyeizuigbo, 2010). Bandura (1997) postulates that highly efficacious individuals tend to tackle tasks that are more challenging, employ better strategies; put forth more sustained effort and are more persistent in the face of obstacles, setbacks and difficulties. self efficacy increases the probability of success through its effects on sustained effort and stamina. In addition, there is evidence that high self-efficacy minimizes stress and contributes to good health (Onyezuigbo, 2010; Salami, et al., 2010).

Sense of coherence (SOC)Sense of coherence (SOC) is a theoretical construct defined to represent the belief that what happens in life is comprehensible, manageable and meaningful, and hypothesized as a flexible and dispositional orientation that enables successful coping with adverse experience and the maintenance of good health (Wainwright et al. 2006).

Sense of coherence (SOC) presented a new dimension of looking into the concept of health. It focuses on factors that support human health and well-being in contrast to factors that cause disease (Eriksson \& Lindstron, 2007). Antonovsky (1993) posited that SOC is not a particular coping style, but a high SOC may prevent stress-associated tension from developing into health problems, because individuals with a high SOC are more likely to adapt a coping strategy that is efficient for dealing with stressors. Previous studies provided evidence that sense of coherence correlated positively with psychological well-being and life satisfaction (Ying et al., 2007; Mikolajczyk et al., 2008).

\subsection{Background of the Study}

Nigeria is the most populous country in sub-Sahara Africa with an estimated area of $923,773 \mathrm{~km}^{2}$ (National Bureau of Statistics, 2010; Aregbeshola, 2011), comprising of 36 states and a population of 152 million people (Akuede et al., 2012). Based on natural landscape, Nigeria is divided into three regions namely: Northern region, Western region and Eastern region, by the intersection of the River Niger and the River Benue before terminating into the Gulf of Guinea (Philips, 2004) Fig. 1. The geographical location of the Federal Republic of Nigeria is on the Gulf of Guinea in the West Africa. It is between Benin in the west and Cameroon in the east, Chad in the north east and Niger in the north-west.

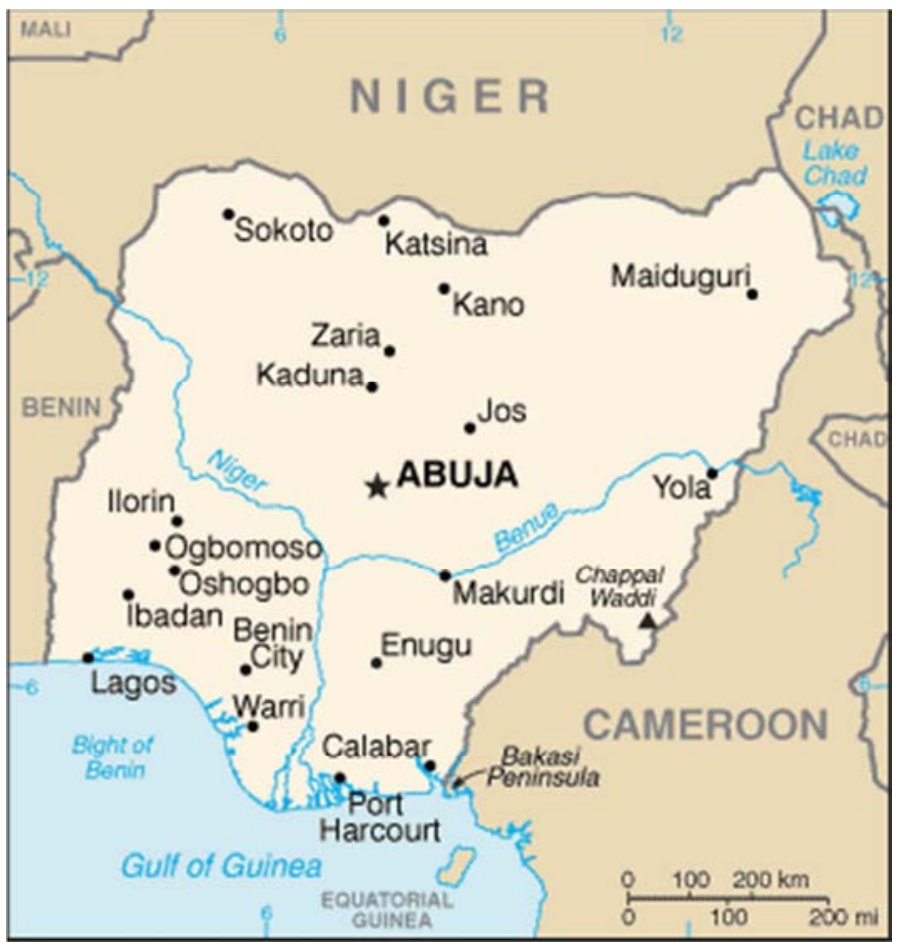

Figure 1. Map of Nigeria showing the three regions by the intersection of the Niger River and Benue River. Available at: http//: mans.com [Date of accessed $20^{\text {th }}$ July, 2014]. 
The diversity of climates observed in Nigeria are aridity in the north, tropical in the centre, and equatorial in the south, with a maximum temperature above 32 degrees Celsius in the north (Walker, 2008). The annual rainfall is more in the south 2000 millimeters than in the north 500-700millimeters (Aregbesola, 2011). Therefore, the northern region is exposed to a prolonged heat, prolonged drought, and dry seasons, this hash environmental conditions is expected to affect growing of crops, vegetation, and grazing of animals, sources of domestic water and sanitation and farming among others. Consequently, it is assumed that the environmental conditions will affect both the physical health and psychological health of Nigerians living in the northern region, differently from those living in the other two regions (Terrass and Benjelloun, 2010). However, no comparative cultural study exists in Nigeria that examines the health and lifestyle differences of the three regions, by gender across any selected population group. In addition, Nigeria is multiethnic, organized into three major ethnic groups that included Igbo in the east, Yoruba in the west and Hausa/Fulani in the north (Bangdiwala et al., 2010; Ucha, 2010).

The current study also focused on gender differences in health status and lifestyle behaviours. The female gender in Nigeria has been subjected to various degrees of discrimination, isolation, intimidation and stigmatization in comparison to their male counterparts (Mancini, 2009) and this may have a detrimental effects on mental and physical health. For instance, the first question people usually ask with regard to a new-born child in Nigeria is: "Is it a boy or a girl?" (Omoregie \& Ihensekhien, 2009). Such a question carries a great deal of significance for the child's entire life. A study of this nature for the first time could provide evidence of health inequality by gender which may draw the attention of stake holders for urgent redress.

\subsection{Why the Study Was Focused on University Students in Nigeria}

Measuring the health status of university students in Nigeria is important to ascertaining health intervention effectiveness, monitoring progress, and as a critical step in measuring the health of the general population. Moreover, in Nigeria, the population of young adults in the university are significant about $(8.1 \%)$ of the total age group (15-64) that constitute about $(54.9 \%)$ of the total population of Nigeria (National Bureau of Statistics, 2010). These are young adults, and the attitude and lifestyle behaviours of university students are not only important for them, but also relevant to policies concerning health. In addition, students are young, and there is evidence that risky lifestyle at an early age can reflect the health of the society they are going to live in the coming years (Steptoe et al., 2002; Garrusi et al., 2008) and university years may present a unique opportunity to develop healthy lifestyle behaviours in a particular manner. Also, Nigeria is a developing economy and in recent times has been designated the largest economy in Africa (Aregbeahola, 2011, WHO, 2012;), consequently, it will require a large percentage of healthy intellectuals who will contribute to the development of Nigeria.

Furthermore, students are future leaders and potential policy makers, their health and wellbeing need to be guided at this most important phase of their development, and equipped with the right knowledge to be able to distinguish between healthy and unhealthy lifestyles (Garrusi et al., 2008; Schmidt, 2012). However, for several reasons, this study was centered on university students in Nigeria. Literature review indicated few studies on the health status and lifestyles behaviours of university students in Nigeria, although none of this studies was based on the cultural differences among the three ethnic groups. However, while these studies have provided valuable data about university student's health issues, most of these studies have considerable limitations that necessitated further studies. Some of these limitations that warranted the current are:

\section{Convenience sample}

Most studies on students in Nigeria are based on convenience sample (e.g. Onyechi and Okolo, 2008; Onyezugbo, 2010). In this case, the researcher might select participants based on those that are easily available and by virtue of their easy accessibility to him. In other words, it has been noted that if the method used to select the sample is not random, there is the probability that human judgement will affect the selection process, making some members of the population more likely to be selected than others (Saunders et al., 2000; Bryman, 2008). When a study is based on such a bias, Bryman, (2008, P. 183) maintained that "the findings may be valuable, but the problem with convenience sampling strategy is that it is impossible to generalize." Consequently, there is a need to repeat studies that are not based on a nationally, randomly selected probability sample, that can be generalized to the students population in Nigeria. Moreover, Hicks et al. (2013) warned that when studies are conducted from sample taken from a single university, that special care should be taken not to generalize the findings of such a study to other students population that are not similar in nature. The current study is based on a nationally representative sample among university students in Nigeria. Sample size Literature shows that most previous studies on university students' population in Nigeria employed small sample size (e.g. Alkandari, et al., 2008; Onyechi and Okolo, 2008). Sample size is important because it is related to effect size; which is the ability of a test to detect the probability level at which result outcomes are said to be statistically significant. It is also related to the power of a test, which is the ability of a test to detect even the smallest effect size, (Boslaugh and Watters, 2008; Field, 2009) and large sample size increases power (Cohen, 1992). The current study is based on a large sample $(n=1549)$ of students from six different universities from the three main regions in Nigeria.

\section{Non-validated instruments}

Most of the previous studies employed measurements that were specially designed for their particular study. Because such measures have not been generally validated in other 
student's sample, it is difficult to compare results from such studies with others.

Cultural comparative studies

None of the studies in Nigeria examined regional differences with regard to student's lifestyles and health status. Most of the studies are based on a single region with no investigation of interaction for inter or intra ethnic effect (e.g. Adewuya, et al., 2006; Onyechi and Okolo, 2008; Onyezugbo, 2010). The need for inter-cultural studies have been emphasized based on the reported differences in health across ethnic groups (Erens et al., 2001).

The aim of this study is to better understand the prevalence of depressive symptoms, life satisfaction and cognitive health status among university students in Nigeria, by gender and ethnicity across- sectional and cross cultural study of university students in Nigeria was undertaken, which to our knowledge is the first of its kind in Nigeria. Inter-cultural comparative studies on student's lifestyles and health status will contribute to the improvement of health of university students, especially in developing countries where there is paucity of research, among the students population.

\section{Research Methods}

\subsection{Consent and Confidentiality}

A letter for approval was presented by hand directly to each Vice Chancellor (VC) of the participating universities in Nigeria. The letter contained the required information concerning the research: title, objectives and the data collection techniques. The letter also explained that the participants consent would be sought before administering the questionnaire, and that their confidentiality will be assured by employing a self-anonymous questionnaire, which does not ask participants name, address or any other form of identification. The letter also explained that the participants have a right to withdraw from the study at any time without any legal implication. The same information was passed to students before data collection with the questionnaire.

\subsection{Sample Size}

This is a cross sectional survey, with students selected from the three major ethnic groups/regions in Nigeria, across all the three university categories (federal, state, and private universities). A questionnaire was sent to 2500 male and female university students in Nigeria during a class lecture and 2112 participants completed and returned their questionnaire, a total of 318 potential participants did not return their questionnaire, while 563 responses were judged to be invalid due to missing of important data (e.g. gender /and or ethnicity) which was the basic criteria for the data analysis. One thousand five hundred and forty nine respondents provided all the required data correctly. The overall participation was about $84.5 \%$.

\subsection{Testing of the Research Instruments}

The entire component of the current study was tested, before beginning the main study. According to Polit \& Hungler (1995, p. 38) "It is necessary to assess the adequacy or the inadequacy of the data collection plan, to test the technical equipment intended for use in the study and to establish the understanding and acceptability of questions by respondents." Consequently, prior to the commencement of data collection for the current study, a convenience sample of $(\mathrm{n}=10)$, Nigerian students at the University of Gloucestershire, 5 males and 5 females were selected to proof read the questionnaire and test the measurement scales for suitability. As recommended by Bryman, (2001, p. 155) that it is best, "if the researcher can select a small set of respondents, who are comparable to members of the population from which the sample for the main study will be drawn."

However, the researcher explained to each participant the aim and objective of the main study and the reasons for testing the research instruments. However, Bryman (2001) maintained that the desirability of testing the research questionnaire is not solely to do with trying to ensure that survey questions operate well; that it has a role in ensuring that the research instruments as a whole function well. Those Nigeria students were given the adopted questionnaire and were asked to proof read them and to make comments with regard to the clarity of the items, and to check wordings for abusive or provocative languages, even on the time it will take to finish the exercise. Their comments and recommendations were taken into consideration, before starting the main study.

\subsection{Multistage Sampling Strategy for Data Collection Sampling of Universities}

There are three categories of universities in Nigeria namely: Federal Universities, State Universities and Private Universities. To achieve a national student's representative sample, this study sampled students from each of these three university categories. To our knowledge, this is the first time that students are sampled from the three university categories in Nigeria, in a comparative study. The researcher approached the office of the Federal Ministry of Education in Nigeria and obtained a comprehensive list of all the registered higher education institutions in Nigeria. There are 102 registered universities in Nigeria according to the National University Commission (NUC, 2010), comprising the three different university categories (Federal, State and Private) within the three main geopolitical zones in Nigeria Northern (Hausa) Southern (Yoruba) and Eastern (Igbo) that constitute the Federal Republic of Nigeria (Bangdiwala et al., 2010)The universities were then stratified into three categories, and all the universities in each category were named, numbered, and put in a different bag. Then the researcher randomly selected two universities each from each of the three university categories. The overall result yielded six universities see Table 1. 
Table 1. Sampled universities and courses of study.

\begin{tabular}{llll}
\hline University categories & Federal Universities & State Universities & Private Universities \\
\hline Sampled & Obafemi Awolowo University & Osun State University & Obon State University \\
Universities & University of Uyo & Akwa Ibom State University & Oduduwa State University \\
Sampled & Medicine & Accounting & Microbiology \\
courses & History & Agriculture & Economics \\
\hline
\end{tabular}

\section{Sampling of students course of study}

The Dean of Students Office (DSO) in participating universities provided the researchers with a list of all courses offered to undergraduate students in each academic semester according to the course level. These courses were stratified according to categories (Federal, State and Private) universities respectively. Then in each university category, the students' courses were adjusted for similarities, by merging different but similar departments together (e.g. microbiology, agricultural sciences, chemistry, botany, zoology and physics into the department of science) so that similarities will be achieved in all university categories. Then, two courses of study with regard to their respective universities were selected at random from a box specific for each university category and the outcome of these random sampling is shown in Table 1.

Sampling of academic year

Students' year of study was stratified into (1st, 2nd, 3rd, 4th, 5th, 6th) academic years. However, the cut-off year for the study was fixed at 4 th year. In other words, the researcher selected participants from academic years (1-4). This cut-off point enabled participants to show similar characteristics. For example, while department of medicine has students up to years (1-6) whereas microbiology and accounting departments have students only and up to years (1-4) academic programme. Therefore fixing a cut-off year at (1-4) ensured identical sample with similar experiences. Other studies (e.g. EL-Gilany et al., 2008) applied similar cut-offs in students population.

\section{Sampling of participants}

A total of $(n=2500)$ students sample of both male and female was given a questionnaire. To ensure that these samples have equal representation by institution, by course of study and by the academic year of study, the following steps were taken: First, the intended sample of $(n=2500)$ was shared equally among the three university categories resulting in $(n=833)$ participants estimated from each university category (Federal, State and Private). Second, since two universities were recruited from each category, consequently, $(\mathrm{n}=833)$ participants were shared into two, allowing a sample of $(n=416)$ from each participating university. Third, since two disciplines were sampled from each participating university, consequently $(n=416)$ was shared into two, allowing $(n=208)$ participants to be recruited from each academic discipline. Finally, since four academic years were shortlisted (cut off point) from each academic discipline, consequently, the sample $(n=208)$ was shared into four allowing $(\mathrm{n}=52)$ students to be recruited from each academic year (e.g. 1, 2, 3, \& 4). All the students in each lecture room were given a questionnaire, the recruitment exercise for each year goes on, until the estimated number of participants was met. EL-Gilany et al. (2008) applied similar strategy in a students' population.

\subsection{Measures}

General Self-Efficacy Scale: The GSES-10 item psychometric scale used in the current study was designed to assess optimistic self-beliefs to cope with a variety of difficult demands in life. The scale was adopted from Schwarzer and Jerusalem (1992). It is a 10-item scale which participants responded by indicating their extent of agreement with each of the 10- statements based on a fourpoint Likert scale of: 1 'not at all true' to 4 'exactly true.' Examples of items in the scale include "It is easy for me to stick to my aims and accomplish my goals." According to Schwarzer and Jerusalem (1992) higher score indicates high self - efficacy. The scale indicated a high internal consistency with cronbachs alpha (a) ranging from 0.75-0.90.

Sense of coherence

Sense of Coherence was measured by the Sense of Coherence Scale (SOC-13) (Antonovsky, 1993). shorter version was used that include 13- items and is highly correlated with the long form version of 29 items (Tagay et al., 2006). It is a summary scale with seven Likert-type response categories ranging from 1 to 7 . High scores are associated with higher levels of sense of coherence. In the German version, alpha was 0.85 for SOC-13 (Schumarcher et al., 2002).

\section{Locus of control}

Locus of control was measured with the Intensity Subscale of Levenson's (1981), Internal, Powerful Others and Chance locus of control (IPC) Scale. Five items was adopted, example includes "I am in control of my health.". "Responses are based on 6- point likert type scale ranging from 1 (strongly disagree) to 6 (strongly agree). The scale exhibits moderate reliability $(0.65)$ and have been used in a wide variety of samples (Zawawi and Hamaideh, 2009).

\section{Depressive symptoms}

These items were adopted from Beck Depression Inventory $(\mathrm{M}-\mathrm{BDI}-20)$. It contains a six-point Likert scale measuring its frequency in the last 4 weeks with the two extreme categories labelled as ( $0=$ "Never", to $5=$ Almost always"). Respondents were to rate each of the 20 depressive symptoms according to their perception using a visual analogue scale (VAS) format. The respondents were asked to indicate how frequently they experienced each of 
the 20 symptoms (e.g. 'I feel sad'). The M-BDI - 20 was validated by Mikolajczyk et al. (2008), they also reported high internal consistency reliability (Cronbach's alpha of $0.90,0.92 \& 0.87$ ) in Germany, Poland and Bulgaria respectively. The cut of score of M-BDI $\geq 35$ is considered depression (Schmitt et al., 2006, Mikolajcyzk et al., 2008). Similar cut off was used in the current study.

\section{Life satisfaction:}

Life satisfaction was measured with the satisfaction with life scale (SWLS) adopted from (Diener et al., 1985). This is a five item scale assessing positive cognitive appraisals of life in general, with items (e.g. "In most ways my life is close to the ideal") rated from 1 (strongly disagree) to 7 (strongly agree). A test - retest reliability of 0.82 and internal consistency of 0.87 were reported by (Dorahy et al., 1998) in their study. The cut -off point recommended are: (1). Satisfied with life are scores greater than 21 (2). Dissatisfied with life are scores from 20.

\subsection{Statistical Data Analysis for the Present Study}

Students' responses to the questions in the present study were transferred to the SPSS statistical package, 20.0 versions for data analysis. All responses where sex and ethnicity were not indicated were automatically excluded from the data analysis. For 'normality,' scale data were first checked using Kolmogrove-Simonov test to ensure that they were acceptably normal before parametric statistics were used. On the other hand, Levene's test was used to ensure 'homogeneity of variance' before conducting ANOVAs test. the effect sizes of the tests have been added and commented within the result section. To answer the research questions and achieve the research objectives, three separate tests were conducted: Descriptive statistics, non-parametric tests and parametric tests for comparing means.

Descriptive statistics: preliminary data analysis of this study was conducted with descriptive tests, it also enabled for the screening and cleaning the data and to check the entire data set entered into the SPSS for errors. In addition, descriptive statistics made it possible for the description of the characteristics of the sample in percentage, mean, and standard deviation. Chi square test was used to examine the relationship between variables. In addition, the study also employed both the one-way ANOVA, two- way ANOVA to examine the differences and interactions.

\section{Results}

\subsection{Cognitive Health Indicators}

Table 2 presented the result of a two-way ANOVA of cognitive health variables (with inserted descriptive statistics) that includes sample, means and standard deviations for both sex and ethnicity together with interaction effects and main effects for sex and ethnicity. With regard to sense of coherence (SOC), in addition to the assessment of student's total SOC score, an SOC sub category (meaningfulness) was also examined (Table 2). results showed that the mean SOC score for the overall sample was (10.80). The two- way ANOVA indicated that there was a significant sex*ethnic effect for the SOC total sum. This effect is shown graphically in (Figure 2). In addition, there was a significant main effect for sex and ethnicity, where males were lower than females.

Table 2. Two-way ANOVA showing mean (SD) of cognitive health items by sex and ethnic.

\begin{tabular}{|c|c|c|c|c|c|c|c|c|c|c|}
\hline \multirow{2}{*}{$\begin{array}{l}\text { Ethnic } \\
\text { Variable }\end{array}$} & \multicolumn{3}{|c|}{ Female (mean (SD) } & \multicolumn{4}{|c|}{ Male (mean (SD) } & \multirow{2}{*}{$\begin{array}{l}\text { Sex* ethnic } \\
\text { P- value /partial }\end{array}$} & \multirow{2}{*}{$\begin{array}{c}\text { Sex } \\
\text { Eta squared }\end{array}$} & \multirow[t]{2}{*}{ Ethnic } \\
\hline & Sample & Hausa & Igbo & Yoruba & Hausa & Igbo & Yoruba & & & \\
\hline \multirow{2}{*}{ SOC-total } & 53.57 & 53.91 & 56.80 & 53.50 & 53.56 & 52.30 & 50.80 & & & \\
\hline & $(10.80)$ & $(11.50)$ & 10.80) & $(10.80)$ & (10.71) & (11.00) & $(9.30)$ & $0.022 \% .006$ & $0.001 \% .014$ & $0.001 \% .009$ \\
\hline \multirow{2}{*}{$\begin{array}{l}\text { SOC- } \\
\text { meaning }\end{array}$} & 15.43 & 15.32 & 16.14 & 15.33 & 15.92 & 15.25 & 14.61 & $0.006 \% .006$ & $0.104 / .001$ & $0.009^{\star} / .006$ \\
\hline & $(4.07)$ & $(4.53)$ & $(3.58)$ & $(3.74)$ & $(4.41)$ & $(4.23)$ & $(3.81)$ & & & \\
\hline \multirow{2}{*}{ Self-efficacy } & 31.16 & 30.58 & 31.72 & 30.69 & 32.15 & 30.69 & 31.41 & $0.001 \% .013$ & $0.105 / .002$ & $0.613 / .001$ \\
\hline & $(5.05)$ & $(4.77)$ & $(4.85)$ & $(5.55)$ & $(5.16)$ & $(4.93)$ & $(5.01)$ & & & \\
\hline \multirow{2}{*}{ LOC -total } & 30.99 & 31.23 & 31.92 & 30.27 & 30.72 & 31.74 & 31.03 & $0.818 / .001$ & $0.286 / .001$ & $0.001 \% .014$ \\
\hline & $(6.45)$ & $(6.31)$ & $(7.00)$ & $(5.97)$ & $(6.04)$ & $(6.53)$ & $(6.60)$ & & & \\
\hline \multirow{2}{*}{ POHLOC } & 33.37 & 3.38 & 3.16 & 3.36 & 3.42 & 3.74 & 3.17 & $0.001 / .011$ & $0.058 / .002$ & $0.123 / .003$ \\
\hline & $(1.48)$ & $(1.30)$ & $(1.40)$ & $(1.41)$ & $(1.52)$ & $(1.73)$ & $(1.49)$ & & & \\
\hline
\end{tabular}

One -way ANOVA conducted for female students alone showed a significant main effect for region $(\mathrm{P}=0.003)$ and a post hoc Tukey test showed that Igbo females had a high SOC sum than both Hausa and Yoruba $(\mathrm{P}<0.05)$. However, the effect size was very small $(\mathrm{r}=0.009)$. On the other hand, the analysis for male students showed a significant regional effect $(\mathrm{p}=0.012)$, where Yoruba males showed a significant differences with Hausa males $(\mathrm{P}<0.05)$. With regard to sense of coherence (meaningfulness), which examined how students are able to make meaning of their life events, in overcoming stress and depression (Table 2), the result showed a significant sex*ethnic effects for SOC-meaning (Figure 2). There were also significant main effects for ethnic $(\mathrm{P}<0.05)$ but not for sex, which shows no significant differences. The analysis also showed that the mean score for males was lower than that of females. 


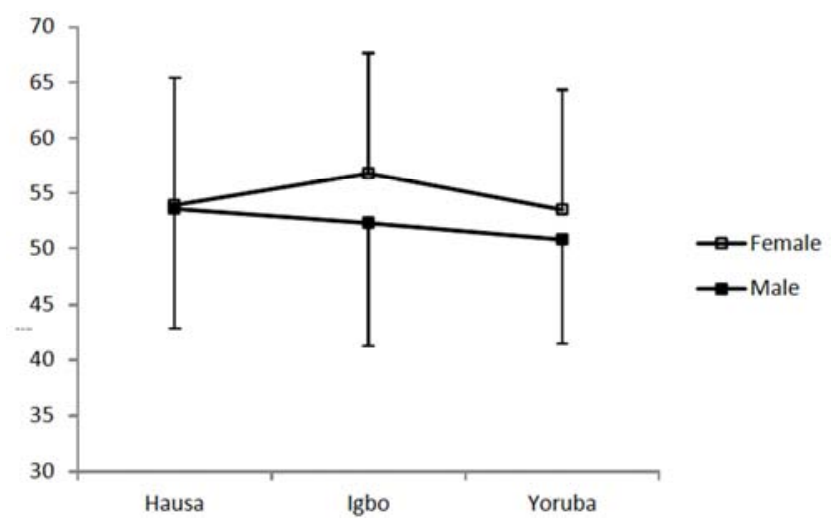

Figure 2. Shows the main effects for sex and ethnicity for SOC (sum).

The above graph shows one- way ANOVA output plot for SOC (sum) main effect for sex and ethnicity. Error bars are one SD.

* Igbo females was significantly higher than both Hausa and Yoruba females $(\mathrm{P}<0.05)$

* Yoruba males was significantly lower than Hausa males $(\mathrm{P}<0.05)$

One- way ANOVA for females showed no significant main effect $(P=0.072)$ and post hoc Tukey tests showed no significant differences. However, the analysis for male students showed significant ethnic effects (P 0.002) and post hoc Tukey tests showed that Yoruba was significantly lower than Hausa and Igbo ethnic groups.

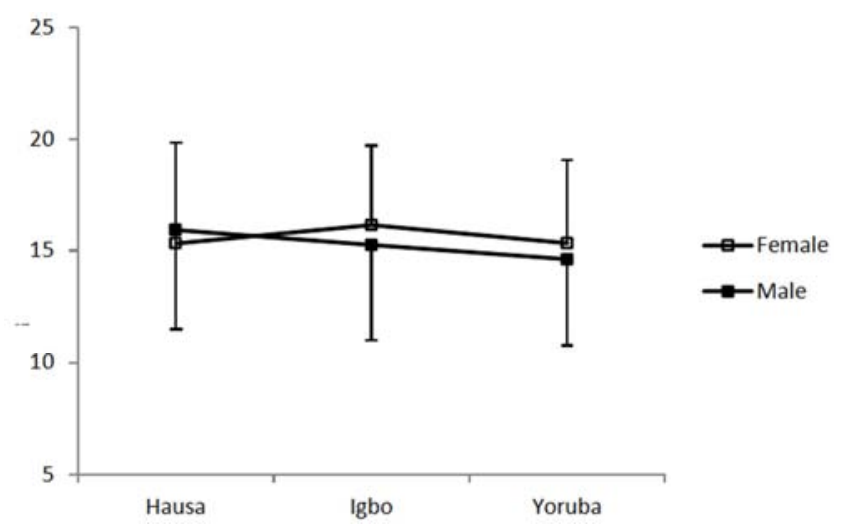

Figure 3. Shows the sex *ethnic effect for the SOC sub group (meaning).

The above graph shows one -way ANOVA output plot for SOC (meaning) sex and ethnic. Error bars are one SD.

*Yoruba male was significantly different and lower from Hausa $(\mathrm{P}<0.05)$

*No significant differences among female students at $\mathrm{P}>0.05$

With regard to self-efficacy, the two-way ANOVA showed sex*ethnic interaction effect with no main effect for sex and ethnicity. However, the result showed that males were higher than females (Table 2 Figure. 3).

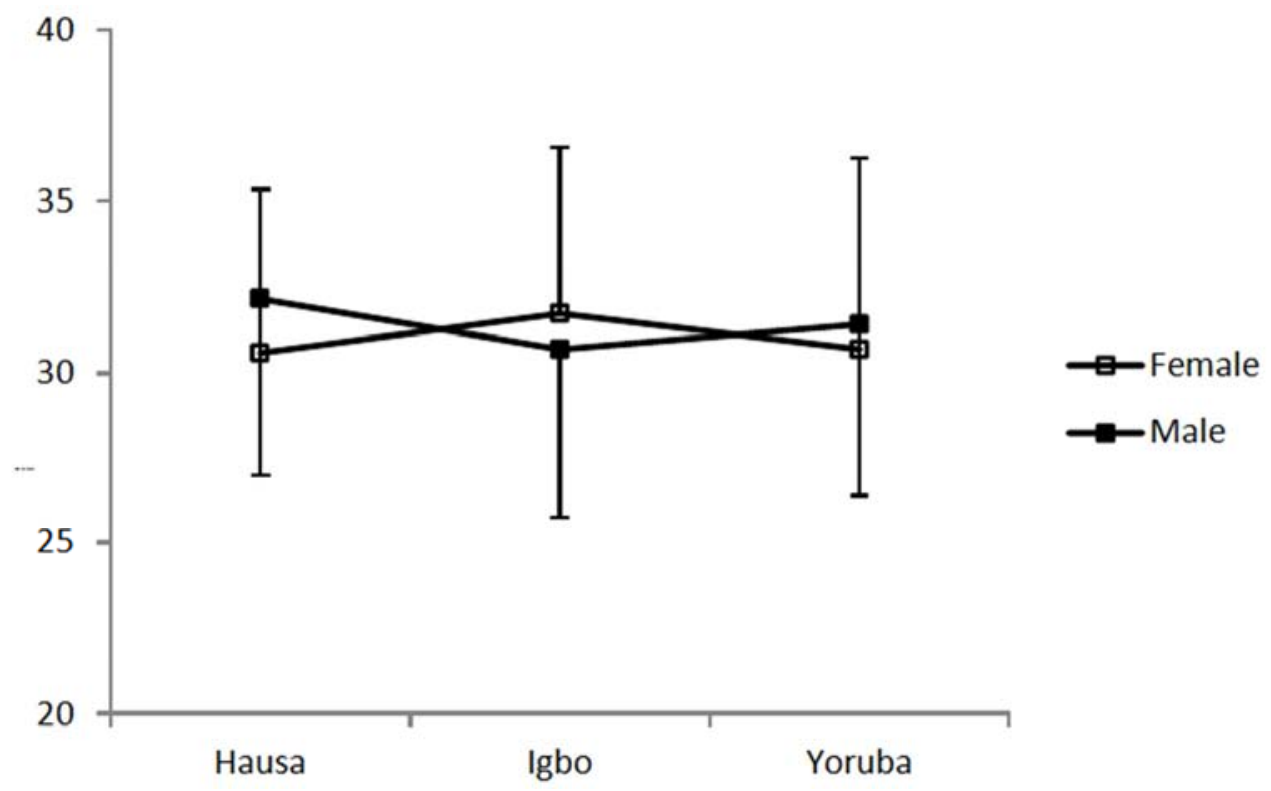

Figure 4. Shows sex*ethnicity effect for self- efficacy.

The above graph shows one- way ANOVA output plot for sex and ethnic effects for self- efficacy. Error bars are one SD.

*Igbo females was significantly higher than Hausa and Yoruba females $(\mathrm{P}<0.05)$.

*Hausa males was significantly higher than Igbo $(\mathrm{P}<0.05)$.

One-way ANOVA for females showed an ethnic effect (P $<0.007)$ and a post hoc Tukey tests shows that Igbo females were significantly higher than others females $(\mathrm{P}<0.05)$. One- way ANOVA for male students showed an ethnic effect $(\mathrm{P}<0.005)$ and Igbo males were significantly lower than others $(\mathrm{P}<0.05)$. With regard to locus of control (LOCtotal) the mean score and SD for the overall sample was presented in (Table 2). When a two-way ANOVA was conducted, the result showed no sex*ethnic effects, for the LOC total score. In addition, there was no main effect for sex, but there was a main effect for ethnic, where Igbo males scored higher than both Hausa and Yoruba males. However, when the powerful others health locus of control (POHLOC) an LOC sub-group, was investigated, the overall score was high (Table 2). 


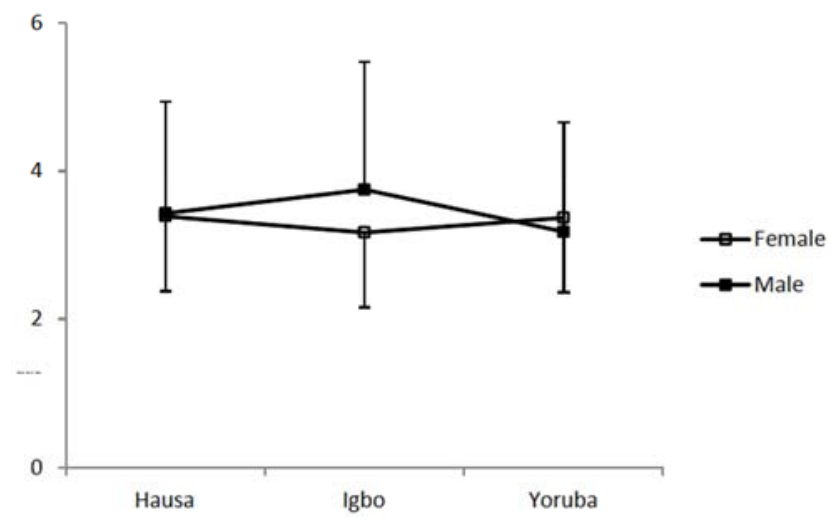

Figure 5. Shows the sex*ethnic main effects for (POHLOC).

The above graph shows one- way ANOVA plot for sex and gender main effects for (POHLOC). Error bars are one SD.

*Igbo males significantly differs from Yoruba males $\mathrm{P}<0.05$

* Females showed no significant differences by ethnicity $\mathrm{p}>0.05$
When a two-way ANOVA was conducted for the sample, the result showed a significant gender and ethnic effect for POHLOC. The result also showed no main effect for sex and ethnic (Figure 5), by sex and ethnic. One-way ANOVA for females showed no ethnic effect $(\mathrm{P}=0.093)$ and post hoc test showed no significant differences. However, one-way ANOVA for males showed a significant main effect for ethnic $(\mathrm{P}<0.001)$, and a post hoc test showed that Igbo males had a significant higher score than Yoruba $(\mathrm{P}<0.001)$ in POHLOC.

\subsection{Mental Health Indicators}

Table 3 presents the Chi- square analysis of students' mental health indicators by sex and ethnic groups. The results also show the analysis based on the overall sample. The results presented in frequency and percentages.

Table 3. Frequency and percentage (\%) of mental health indicators by sex and ethnicity.

\begin{tabular}{|c|c|c|c|c|c|c|c|}
\hline VARIABLE Sample & Female & Male & P/PHI & Hausa & Igbo & Yoruba & P/PHI \\
\hline \multicolumn{8}{|l|}{ Depression } \\
\hline Low < $351065(69)$ & $535(63)$ & $525(76)$ & \multirow[t]{2}{*}{$0.001 \% .138$} & $315(59)$ & $396(73)$ & $357(75)$ & \multirow[t]{2}{*}{$0.001 \% .148$} \\
\hline High > 35484 (31) & $313(37)$ & $169(24)$ & & $215(41)$ & $147(27)$ & $120(25)$ & \\
\hline \multicolumn{8}{|l|}{ Life satisfaction } \\
\hline Dissatisfied 522 (34) & $288(34)$ & $234(33)$ & \multirow{2}{*}{$0.810 / .006$} & 208(39) & $153(28)$ & $162(34)$ & \multirow{2}{*}{$0.001 \% .097$} \\
\hline Satisfied 1027 (66) & $560(66)$ & $467(67)$ & & $322(61)$ & $390(72)$ & $315(66)$ & \\
\hline
\end{tabular}

NB. $p / p h i$ indicates $p$ value for significant, where $p=p$ value, $\mathrm{phi}=$ effect size

With regard to depression (Table 3), results showed that while one-third of the total sample of students reported depression two-third of the sample, reported low depression. The result also indicated a significant association between male and female students with more females reported depression compared to male students.

The effect size was small $(\mathrm{r}=.138)$, indicating no major differences in the actual number of students that suffered depression by gender. In addition, when the analysis was compared by ethnicity, the Chi- square test for independent indicated a significant association between students' reported depression and their ethnic origin. The result indicated that twice as many Hausa students compared to Igbo and Yoruba reported depression (Figure 6), and the result also showed that Hausa female students are the most depressed and this was followed by the Igbo female students in the sample (Table 3).

However, among the male participants in the sample, the Yoruba male students indicated to be the most depressed. It is interesting to note that while there was a significant gender differences in depression among the Igbo and the Hausa ethnic groups, there was no significant differences between the male and female students among the Yoruba ethnic group.

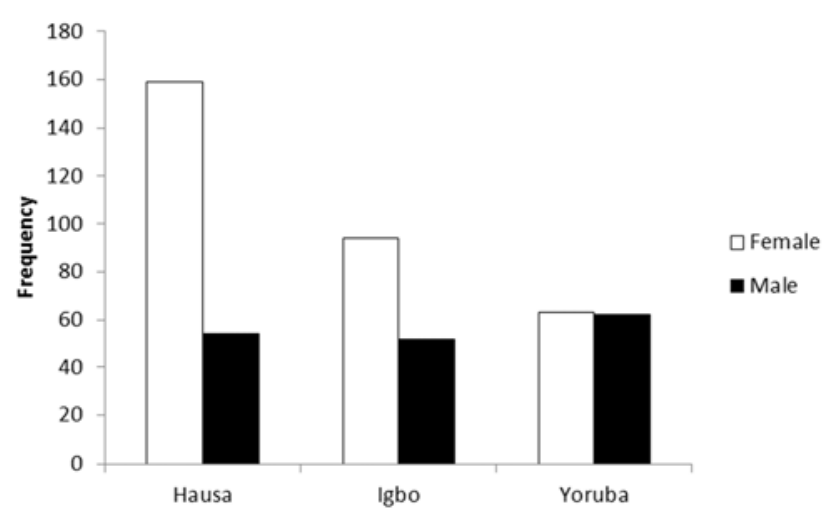

Figure 6. Frequency of those reported as depressed by gender and ethnicity.

With regard to life satisfaction (Table 3), the result showed that more than two-third of the students indicated that they were satisfied with the events in their life as against the onethird of students that were dissatisfied with their life events. When the students' life was compared by gender, the result showed no significant association between the way male and female students perceived their satisfaction with life. However, the analysis by ethnic group showed a significant association between students' ethnic groups and their perceived life satisfaction. The result showed that more students from the Igbo ethnic group indicated being satisfied with the events in their life, whereas Hausa ethnic group indicated the poorest score in students' life satisfaction scale. 
Figure 7 represents the analyses graphically, showing the frequency of the satisfied and the not satisfied by ethnic groups. The graph indicates that more students from Igbo ethnic group are satisfied with their life events. The graph also confirms that more students from the Hausa ethnic group rated their life events as 'not satisfied' when compared with other ethnic groups.

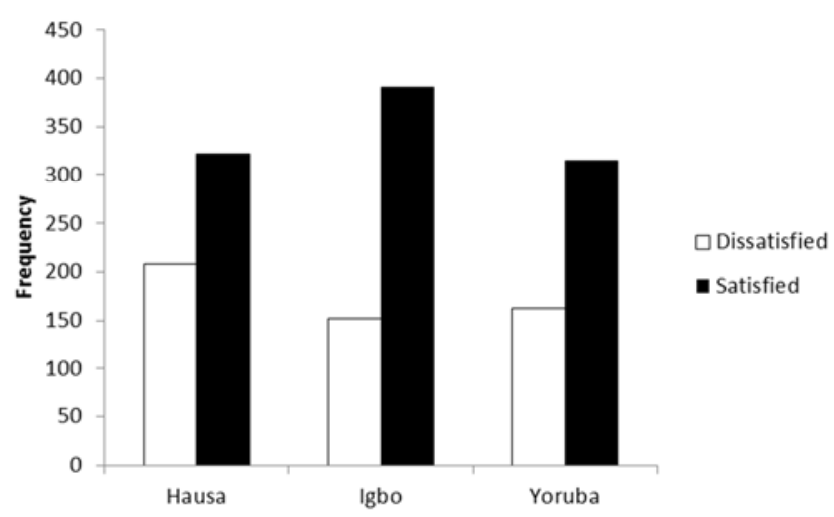

Figure 7. Frequency of those reporting satisfied or dissatisfied with life by ethnic.

\section{Discussion of the Results}

\subsection{Cognitive Health Indicators}

Cognitive health was measured with three items: Selfefficacy, sense of coherence and locus of control (Table 2). for self-efficacy, the data indicated that irrespective of ethnicity, males scored better than females. In addition, further analysis showed that more Hausa males and Igbo females had better scores than other groups and more Hausa females and Igbo males had the lowest scores, than other groups. On the other hand, sense of coherence analysis indicated interaction effects and irrespective of ethnicity, more females in general scored better than males. Further analysis suggest that Hausa males and Igbo females had better SOC scores and Hausa females and Yoruba males had the lowest SOC scores than other groups (Figure 1). The study indicated that cognitive health factors are both sex and ethnicity dependent, but why male students had better self-efficacy and females' better sense of coherence is difficult to explain, and requires the above findings suggest that it is the sense of coherence rather than self -efficacy that is associated more with both psychological and physical health. Similar findings were reported by previous studies (e.g. Ebert et al., 2002, Ying et al., 2007; Mikolajczyk et al., 2008). However, there are other factors to be considered, before further interpretations of the above findings. Similarly, salami (2010) in a study among students in Nigeria $(n=241)$ found that higher depression among the students was associated with low self - efficacy, similar to what was reported among Yoruba male students in the present study. There is a need for more studies on effects of self - efficacy on students health in Nigeria. more studies.

Though there is no direct evidence of the effect of cognitive factors on students' health, in the present study, only possible explanations can be considered. The study suggested a possible positive relationship between better psychological health with cognitive health. For example, the Hausa female students had the lowest scores in both sense of coherence and self-efficacy, and consequently they reported the worst possible health outcome among the ethnic groups. Conversely, the Hausa males, had the best scores in both the sense of coherence and self-efficacy, and the lowest score on the powerful others health locus of control (POHLOC) and consequently this group, reported the best possible health outcome among male and females in other ethnic groups.

However, when Igbo males and Yoruba males were examined closely, with regard to the health impact of cognitive factors, a unique heath outcome was found. The study found that while the Yoruba male students had the lowest sense of coherence, this group reported the highest level of depression, and the lowest scores on life satisfaction among male students other than other groups. On the contrary, the Igbo males scored the lowest on the selfefficacy scale than other groups, but at the same time the result suggest that this group had the highest score on life satisfaction scales, and low depression. The above findings suggest that it is the sense of coherence rather than selfefficacy that is associated more with both psychological and physical health. Similar findings were reported by previous studies (Ying et al., 2007; Mikolajczyk et al., 2008). Although there are evidence that sense of coherence and selfefficacy were associated with good health, reduced stress and depression, and low scores in health complaints due to its cushioning effects on depression (Mikolajcyzk et al., 2008; Gajdosova et al., 2009; Salami, 2010). This needs further investigations.

\subsection{Mental Health Indicators}

The students mental health status was gauged with two variables namely depression and life satisfaction. With regard to depression, the result indicated that the prevalence of depression in the current study was high, the overall sample indicated that $30 \%$ of students reported depression. The analysis indicated main effects for sex and gender, with more females irrespective of ethnicity reported depression than males. The reasons for the high prevalence of depression in the current study might be related to the observations, that university education in Nigeria is associated with difficulties (Omigbodun et al., 2003, Adewuya, 2006). Some of these difficulties are related to poor income status, income insufficiency, poor health and poor accommodation, violence within university campuses by Islamist militants, in addition to poor infrastructure facilities (Sanya et al., 2009; Salami, 2010). However, an earlier study of depression among university students in Nigeria by Adewuya (2006) showed that only (8.3\%) of the sample reported depression. However, the study measured students depression with the MINI, which is used mainly for hospitalized patients in measuring chronic and 
pathological depression (Pinninti et al., 2003). This may in part account for the low prevalence of depression reported in the Adewuya (2006) study. However, Adewuya (2006), conducted his study when there was less terrorism and violent attacks on students in Nigeria, compared to the present time, when to be a student in Nigeria is to live daily in constant fear of being killed or abducted by the militants Boko Haram that want all forms of western education to be banned in Nigeria.

On the other hand, a study among students from different European countries by Mikolajczyk et al. (2008) found that $34 \%$ of Germans $34 \%$ of Polish and $39 \%$ of Bulgarians reported depression with depressive score $\geq 35$. Students' depression in the current study is slightly lower when compared to those European countries reported above. With regard to the studies of Mikolajczyk et al. (2008), the difference in the prevalence of depression between the present study and those European data, may be attributed to cultural differences in the perception and interpretation of depression.

When students depression was compared by sex, there was a significant differences between male and female students $(\mathrm{P}=0.001)$ where female students reported depression more than male students (Table 3 and Figure 6). This situation may be related to the consequences of female education by Boko Halam that are abducting and killing especially female students in Nigeria sending waves of terror across Nigeria (Adebayo, 2014). In addition, cultural norms where females are expected to do all the home works alone together with their academic work. However, Abdel-Khalek and Ansari (2004) argued that female vulnerability to mental health problems is associated with a type of genetic predisposition, rather than purely environmentally sex differences. Other studies postulated that women in general are more prone to over report medical symptoms than men (Abdel-Khalek \& EL Ansari, 2004; Stock et al., 2007). Consequently, there is a need for more research on students' depression, especially in a multi-ethnic nation like Nigeria.

Results showed a negative relationship between students reported depression and their life satisfaction status. Earlier studies indicated that low life satisfaction and poor quality of life predicts the onset of depression, and psychological disorder up to two years prior to diagnosis (Huebner, 2004). In the current study most students from the Hausa ethnic group reported dissatisfaction with life, which may have contributed to the high prevalence of depression reported by that ethnic group (Figure 6\&7). However, there is a need for more research to establish if depression predicts life dissatisfaction or the other way round. On the other hand, there is evidence that good mental health correlated positively with high scores in student's life satisfaction and quality of life (Diener et al., 2005; Viren et al., 2007). The findings of the present study supported previous studies(e.g. Stock et al., 2007; Marshall et al., 2008; Sabbaah et al., 2013), that there is cultural and ethnic differences in students perception of life satisfaction. However, the current study differs from the findings among Turkish students in a study by Mathney et al. (2004) which reported no ethnic differences.

\section{Conclusion and Limitation}

This study focused on the prevalence of mental health status and cognitive health behaviours, and prevalence of these factors by sex and ethnicity among university students in Nigeria. The uniqueness of the present study is that, for the first time, students data were analysed with interaction effects and main effects in Nigeria. Consequently, literature evidence indicates that the findings from this study have not been presented in Nigeria, which makes comparison with previous studies difficult. However, the multi-ethnic and multicultural composition of Nigeria, demands an understanding of how they interact with sex to determine health inequality by sex and ethnicity in Nigeria, especially among university students, for the first time.

The result of the study indicated that the prevalence of health status and cognitive behaviours among the sample differs between male and female students (main effect) and most important, these differences exist, between ethnic groups and within the same ethnic group (interaction effects). These findings are unique as it suggests that a linear intervention plan for students health in Nigeria will not be effective unless it is based on specific targeted groups. For example, intervention for depression among Hausa female students must be specific for this group. The result indicated no differences between male and female students, with regard to reporting depression among students from the Yoruba ethnic group (Figure 6). This finding is unique as no similar report was found in previous literature, and the present study is not able to provide an adequate explanation.

However, to provide better interventions in the future, it will be important to gain a better understanding of the factors surrounding the mental health condition of Yoruba students by conducting future research on the Psychological health among this ethnic group in Nigeria. However, it is possible to link the high depression reported by students from the Hausa ethnic group to the terror activities initiated in Nigeria by Boko Haram and other militants which has been found to increase fear and anxiety The outcome of the interaction effects and main effects of the present study indicated that the propensity for both mental and cognitive health was sex and ethnicity dependent. This is one of the unique contributions of the present study. By employing interaction effects and main effects in a large sample (n $=1549$ ), this study presents a valid arguments on the health status of students within and across the ethnic groups in Nigeria. In addition the result suggested that the health of female students is poor when compared with those of male students.

So many reasons can be attributed to this observation, including the problems and difficulties associated with females education in Nigeria, such as the obstacles imposed by the Islamist militants that banned western education for females in Nigeria. Another problem is cultural. Women are 
over laboured in Nigeria, because little value is attached to their life compared to males and consequently female students are forced to combine their high academic workload with the over demanding domestic works, which may have contributed to their general poor health. While more studies are needed to establish these observations, this study suggests that health interventions in Nigeria to be effective should be directed towards ethnicity and cultural changes. For example, the abuse of women and depriving them of good education is rooted in culture, so also is the banning of women from certain physical activities. These cultural norms may have contributed to poor health reported by female students in the present study. However, due to the uniqueness of this study it is difficult to compare the results with others already existing in Nigeria. Consequently, similar studies are needed in Nigeria among university students in order to compare and to understand the cultural contributions to health inequalities in Nigeria.

\section{COVER LETTER}

This study was the first to suggest that the health status of Nigerian university students are dependent on gender and ethnicity (interaction) effects. This study for the first time indicated that the health of female students within the Hausa ethnic group was the poorest compared to other ethnic groups. The study also indicated for the first time that while male students had better self-efficacy, female students had better sense of coherence. Consequently, the study concludes that self-efficacy predicts better mental health than sense of coherence.

The public health important for this paper is that health intervention for university students in Nigeria should not be generalized- but should be based on the health need for a specific group, based on the interaction effects reported, for example mental health intervention for Hausa female students or counselling for Igbo male students on cognitive health.

The fundamental message from this paper is that the main determinants of health among university students in Nigeria are dependent more on ethnicity (cultural differences) than on gender.

\section{Acknowledgements}

The assistance of the Vice Chancellors of the ObafemiAwolowo University, Uyo University, AkwaIbom State University, Obong University, Oduduwa University, Osun State University and the staffs of the IT Centre of the University of Gloucestershire, England are humbly acknowledged.

\section{Contributor}

Dr. Dr. Agwu M. E., originated the study, collected data, performed the analysis and led the writing. Dr. S. B. Drapper, contributed immensely on the SPSS analysis and the interpretation of the results, while Prof. M. D. S. Croix, contributed to the editing of the final draft.

\section{References}

[1] Abdel-khalek A, EL - Ansari W (2004). Gender differences in anxiety among undergraduates from ten Arab countries. Journal of Social Behaviour and Personality, 32 (7), 649-656.

[2] Adewuya AO, Ola BA, Aloba, OO, Mapayi BM, Oginni OO (2006). Depression amongst Nigerian university students. J. Soc. Psy. Psy. Epid., 41; 674-678.

[3] Akinsola MK, Awofala AO (2009). Effect of personalization of instruction on student's achievement and self-efficacy in mathematics word problems. Int. J. Math. Edu. Sci. Tech. 40 (3), 389-404.

[4] Akuede O, Idogho PO, Imonikhe JS (2012) Increasing access to university education in Nigeria: Present challenges and suggestions for the future. The Afri. Sym.12 (1), 3-12.

[5] Aldeen LD, Ibrahim C (2014). Knowledge and practice of dietary and healthy lifestyle in a sample of medical and nonmedical college students in Baghda. World Fam. Med. Journal, 12 (3).

[6] Aniebue P, Onyema G. (2008). Prevalence of depressive symptoms among Nigerian medical undergraduates. Royal Soc. Med. Pre., 38 (3), 157-158.

[7] Antonovsky A. (1993). The structure and properties of the sense of coherence scale. J. Soc. Sci. Med. 36, 725-33.

[8] Aregbeshola RA (2011). The political, economic and dynamics of Nigeria: A synop. Asia. Brief., 39, 1-7.

[9] Bandura A (1997). Self-efficacy: The exercises of control. In Bandura A, Capprara GV, Barbaranelli C, Gerbino M, Pasorelli C (EDS). The role of affective self-regulatory efficacy in diverse spheres of psychological functioning. $J$. Child Dev. 74: 769-782.

[10] Bangdiwala SI, Fonn S, Okoye O, Tollman S (2010). Work force resources for health in developing countries. J. Pub. Heal. Rev., 32: 296-318.

[11] BayramN, Bilgel N (2008). The prevalence and sociodemographic correlations of depression, anxiety and stress among a group of university students. J. Soc. Psy. Psy. Epid., 43, 667-672.

[12] Dahlgren G, Whitehead (1991). In Lewis GH, Sheringham J, Kalim K, Crayford JB (Eds.), Mastering public health: A postgraduate guide to examinations and revalidation. London, Edward Arnold, pp. 277-278.

[13] Dahlin M, Joneborg, N, Runeson, B. (2005). Stress and depression among medical students: A cross-sectional study. J. Med. Edu. 39, 594-604.

[14] David LS (2001) Satisfaction with life among international students: In exploratory study. J. Soc. Ind. Res. 53: 315-337.

[15] Diener E, Emmons RA, Larsen RJ, Griffin S (1985). The satisfaction with life scale. J. Per. Ass. 49, 71-75.

[16] Dorahy MJ, Lewis CA, Schumaker, JF, Akuamoah-Boateng R, DuzeMC, Sibiya TE (1998). A cross-cultural analysis of religion and life satisfaction. J. Ment. Heal. Rel. 1 (1), 37-43.

[17] Dusselier 1, Dunn B, Wang Y, Shelley MC, Whalen DF (2005). Personal, health, academic and environmental predictors of stress for residence hall students. J. Am. Coll. Heal.54 (l). 
[18] Ebert SA, Tucker DC, Roth, DL (2002). Psychological resistance factors as predictors of general health status and physical symptom reporting. J. Psy. Heal. Med. 7 (3).

[19] Ekpenyong CE, Udokang NE, Akpan EE, Samson TK (2012). Double Burden, Non-communicable diseases and risk factors evaluation in sub-saharan Africa: the Nigerian experience. Eur. J. Sust. Dev. 1 (2), 249-270.

[20] Eriksson M, Lindstrom B (2007). Antonovsky's sense of coherence scale and its relation with quality of life: A systematic review. J. Epid. Comm. Heal. 61 (11), 938-944.

[21] Gajdosova B, Orosova O, Geckova MA, Tavel P, Van Dijk JP (2009). Personality dimensions, sense of coherence and selfesteem as Risk/protective factors for smoking among university students. J. Stud. Psy. 15, 2-3.

[22] Garrusi B, Safizadch H, Pourhosseni O. (2008). A study on the Lifestyle of the Iranian university students. Iran J. psy. Behav. Sci., 2 (2).

[23] Gilman R, Huebner ES (2003). A review of life satisfaction research with children and adolescents. J. Sch. Psy. Quart. 18, 192-205.

[24] Huebneri ES (2004). Research on assessment of life satisfaction of children and adolescents. J. Soc. Ind. Res., 66, $3-33$.

[25] Jegede PO (2009). Predictors of JAVA programming selfefficacy among engineering students in Nigerian university. Int. J. comp. sci. Inf. Sec. 4 (1\&2).

[26] Levenson, H. (1981). Differentiating between internal, powerful others and chance. In H. M. Lefcourt (Ed.), Research with the Locus of Control construct. (Vol. 1 pp 15-63) New York: Academic press.

[27] Marshall LL, Allison A, Nykamp D, Lanke S (2008). Perceived stress and quality of life among doctors of pharmacy students. Am. J. Pham. Edu., 15, 72 (6). 137

[28] Mathney KB, Curlette WL, Williams LC, Ferda, A, Coleman AG, Dennis T, Errol H (2004). Coping resources, perceived stress and life satisfaction among Turkish and American university students. Int. J. Str. Manag.9, 81-97.

[29] Michinov N. (2005). Social comparison, perceived control and occupational burnout. Appl. Psy. Int. Rev. 54 (1), 99-118.

[30] Mikolajczyk RT, Maxwell AE, Naydenova V, Meier S, Ansari W (2008). Depressive symptoms and perceived burdens related to being a student: Survey in three European countries. J. Cli. Pract. Epid. Ment. Heal .4 (19).

[31] National Bureau of Statistics (NBS, 2010). The review of the Nigerian economy. Retrieved on May, 2, 2012 from http://www.nigerianstat.gov.ng.

[32] Onyezugbo EU (2010). Self-efficacy and test anxiety as correlates of academic performance. Int. Res. J. 1 (10), 477-480.

[33] Pinninti NR, Madison H, Musser E, Rissmiller D (2003). MINI International Neuropsychiatric Schedule: Clinical utility and patient acceptance. J Eur. Psy.361-364.

[34] Pugliese RR. (1994). Tele course persistence and psychological variables. Am. J. Dist. Edu.8 (3), 2239.

[35] Pullman AW, Masters RC, Zalot LC (2009). Effect of the transition from high school to university on anthropometric and lifestyles variables in males. J. Appl. Phy. Nutr. Metab.34

\section{(2): 162-171.}

[36] Sabbah I, Sabbah, H, Khamis, R, Sabbah, S, Droubl, N (2013). Health related quality of life of university students in Lebanon: lifestyles behaviours and socio-demographic predictors. Open Access Journal, 5 (714), 1-12

[37] Salami SO (2010). Occupational stress and well-being: Emotional intelligence, self-efficacy, coping, negative affectivity and social support as moderators. J. Int. Soc. Res. 3(12).

[38] Salami SO (2010). Occupational stress and well-being: Emotional intelligence, self-efficacy, coping, negative affectivity and social support as moderators. J. Int. Soc. Res. 3 (12).

[39] Schmidt M (2012). Predictors of self-rated health and lifestyle behaviours in Swedish university students. Glob. J. Heal. Sci. 4 (4)1-14

[40] Schwarzer R, Jerusalem E (1992). Self-efficacy in the adoption and maintenance of health behaviours: Theoretical approaches and a new model. Res. Sci. Spor. Exer.32, 5498.

[41] Seyedfatemi N, Tafreshi M, Hamid H (2007). Experienced stressors and coping strategies among Iranian nursing students. BMC Nur. J. 6: 11 .

[42] Steptoe A, Wardle J (2001). Locus of control and health behaviour revisited: A multivariate analysis of young adults from 18 countries. Brit. J. Psy. 92, 659-672.

[43] Stock C, Mikolajczyk RT, Bilir N, Petkeviciene J, Naydenova V, Dudziak, U, Marin-Fernandez B, EL Ansari W (2007). Gender differences in students' health complaints: $A$ survey in seven countries. J. Pub. Heal. 16 (5), 353 - 360.

[44] Ucha C (2010). Poverty in Nigeria: some dimensions and contributing factors. J. Glob. Maj. 1 (1), pp. 46-56.

[45] Van RensburgCJ,Surujlal N (2013). Gender differences related to the health and lifestyle patterns of university students. $J$. Int. Heal. Sci. 18 (1).

[46] Virens S, Tomas CP, Dhachayan IS, Thambu M, Kumaraswami K, Debbi S, Adrian, F. (2007). General health mediates the relationship between loneliness life satisfaction and depression: A study with Malasian medical students. $J$. Soc. Psy. Psy. Epid. 42, 161-166.

[47] Wardle J, Steptoe A, Gulis G, Sek H, Todorova I, Vogele C, Ziarko M (2004). Depression perceived control, and life satisfaction in university students from central- Eastern and western Europe. Int. J. Behav. Med. 11 (1), 27-36.

[48] World Federation for Mental Health. (2009). Depression and HIV AIDS: An Overview of the International Research. Accessed on February, 10, 2010, from http://www.wfmhafriainitatire.org.

[49] World Health organization. (WHO, 2005). Preventing chronic diseases: a vital investment. WHO global report. Geneva: World Health Organization. Retrieved on May, 21, 2013, from

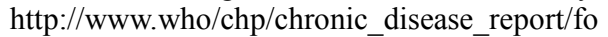

[50] Ying Y, Lee PA, Tsai, JL (2009). Attachment sense of coherence, and mental health among Chines American college students: Variation by migration status. Int. J. Intercul. Rel. 31; 531-544.

[51] Zawawi JA, Hamaideh SH. (2009). Depressive symptoms and their correlates with locus of control and satisfaction with life among Jordanian college students. Eur. J. of Psy., PP. 71-103. 